\title{
Oppression and Violence against Women: An Ecopsychological Perspective
}

\section{Maysar Sarieddine*}

Lebanese American University, Beirut, Lebanon

\begin{abstract}
The issue of violence against women is considered a grave violation of human rights that occurs across race, age, culture, and religion worldwide. It includes any act or conduct that may cause death or physical, psychological, or sexual harm to women - whether in the public or private sphere - that is done solely based on gender. The issue of violence against women has been discussed, debated, lobbied, and fought for in recent decades; and much research on the incidence, reporting, and implications of such violence against women has also been conducted in many regions and countries. These concerted activist efforts led to the first declaration that recognized the need to provide women the rights to equality, security, liberty, integrity, and dignity of all human beings. Even with such global efforts, and despite the existence of laws that punish men who perpetrate violence against women, the problem continues to persist worldwide. Academics thus deem it necessary to determine the underlying causes and motivations for such heinous acts in order to attack the problem at its roots.
\end{abstract}

Keywords: Oppression; Women; Men; Ecopsychology

\section{Introduction}

Oppression of women and violence against women are two experiences whose origins are debatable, but whose existence is anathema to a large proportion of humanity. Some cultures permit or even legislate the oppression of women, while some cultures indirectly allow it [1]. There are a wide range of actions across cultures that perpetuate the oppression of women and the appearance of condoning violence against women [2]. These actions include economic disadvantages, disproportionately lenient sentences or legal ramifications for oppressing women or committing acts of violence against them, difficulty in bringing successful legal actions against perpetrators of oppression or violence against women, laws that treat women differently than men, and general sexism in various segments of society.

Over the past two decades, the treatment of women has been linked to the treatment of nature [2-6]. This conceptualization of the link between how society can behave towards women and how society can behave toward nature was termed ecofeminism, and it is a branch of the broader concept of ecopsychology. On this basis, this paper will first provide a brief background of the history of the oppression and violence against women followed by an overview of ecopsychology. The connection between the two will be explicitly examined, and the ecopsychological perspective of the oppression and violence against women will be reviewed. The purpose of this paper is to examine the link in the literature between oppression and violence against women and society's behavior towards nature.

\section{Oppression and Violence against Women}

This section will provide a background for the discussion of oppression and violence against women. The origins of the two constructs will be presented followed by the factors that perpetuate their existence. While the origins of oppression and violence against women are not agreed upon by all academic researchers, the general perspective relates the early activities and separation of labor based on biological imperatives to the resulting outcomes and the potential for male dominant societies [7]. The separation of roles among the genders began in the earliest phase of human development. In a hunter and gatherer society, the biological differences between men and women determined their role in this type of society [8].
During this separation of roles in society, some authors believe that the male role as a hunter played a significant part in the development of skills that related to the use of weapons and the use of aggression towards a beneficial end $[3,4,9]$. To further this aggressive attitude and the separation between the genders, males in nomadic tribes were responsible for animal breeding. Animal breeding was a key role and was treated in a similar fashion to the place of women in that society [8]. Since men were responsible for they key factors that led to a functioning society, women's roles were reduced to bearing and raising children.

Since men were the gender that explored the limits and boundaries of each individual society, it was men that first encountered other tribes or other cultures and it was men that first explored the concept of increasing one group's power and property through the conquering of another group of people [1]. This was the first step in human society's development towards the goal of accumulating power and property.

The accumulation of property, which was done mostly by force, resulted in a disproportionate distribution of wealth and power among early tribes and cultures. The male gender was viewed as almost entirely responsible for this increase in power [2]. As a result, the male place in society began to become one of power and prestige, which also resulted in the accumulation of wealth, from a very early point in human societal development. While some opponents of feminism have noted that this was a result of male biological dominance, several authors have shown that it was also in large part due to the fact that women were tied down by their role in society as care-givers and agricultural overseers. This place in society prevented women from being free to explore the boundaries of their societies $[1,7]$.

Some societies in which hunting was seen as the sole way of

*Corresponding author: Maysar Sarieddine, Lebanese American University, Beirut, Lebanon, Tel: + 009613 333348; E-mail: maysar@gmail.com

Received: January 25, 2018; Accepted: February 07, 2018; Published: February 14,2018

Citation: Sarieddine M (2018) Oppression and Violence against Women: An Ecopsychological Perspective. Clin Exp Psychol 4:189. doi:10.4172/24712701.1000189

Copyright: @ 2018 Sarieddine M. This is an open-access article distributed under the terms of the Creative Commons Attribution License, which permits unrestricted use, distribution, and reproduction in any medium, provided the original author and source are credited. 
exerting power and gaining prestige have been linked to the treatment of women as beings closer to animals than equals [10]. A few of these societies have been identified as aboriginal cultures in Australia. In that time and place in history, women were not given democratic rights, nor even treated as being productive members of a cooperative society. These obscure societies, ones that are not considered widespread or mainstream among the majority of the world's population, were not alone in subjugating women. African tribes also often viewed women as non-equal members of society. But tribes and cultures that have not developed at the same rate as the industrial world were not alone in this regard either.

Religions, which have been a key sociological force for thousands of years, played a significant role in providing an excuse or a reason for the oppression of women. Judeo-Christian belief structures are not alone in this regard. Arabic, Indian, and Chinese belief structures, to different degrees and extents, also placed women as secondary citizens [10]. The developed world is almost entirely some form of Catholic, Protestant, Hindu, or Jewish. Together, those religions comprise well over $80 \%$ of the world's population and in every one of those religions; the woman's role is seen as unequal to the male role. Religions, however, did not direct the evolution of the developed world and industrialization has, to some extent lessened the dependence on a male-dominated society, but not nearly to the point of being equal. Religions also did not prevent or mitigate the current occurrence of violence against women.

Lerner [10] noted that the general perspective of women as beneath, subservient or unequal to men could have led to a viewpoint that allowed violence against women to become something other than taboo. Only in the most egalitarian societies is there no violence against women. These societies include Buddhism and similar cultures where the role of all living things is seen as equal and men and women live in harmony with nature. This viewpoint will be noted later in this discussion; however, it is important to note that in virtually every other society, there is a disproportionately lenient treatment of violence against women.

In most developed societies, white collar crimes such as bank fraud can carry stiffer sentences than rape. The various forms of violence against women that exist in the world have been linked to the dominant viewpoint of males being superior to females. These forms of violence include intimate partner violence, sexual violence, psychological abuse, and reproductive violence (such as clitorectomies). The similarity among these actions and behaviors is the view that women are not equal to men. The perspective of a lack of equality can pervade a culture's actions and result in either the explicit or implicit permissibility of violence against women. While the 1960's and 1970's provided a foundation for the feminist movement, a link between how male-dominated society treats women and how male-dominated society treats nature did not arise until the late 1980's and 1990's. This link was ecopsychology.

\section{Ecopsychology}

The development of ecopsychology came from the relationship between how man views and treats nature. The tenants of the philosophy are that man can solve environmental problems by living in harmony with nature [11]. The ecopsychology movement that has developed over the past 20 years can mostly be found in the United States; however, there has been growth in the UK, South Africa, and Australia. There are a large number of various practices of the philosophy in which human beings are involved in a more intimate relationship with nature and in which community building, with an eye towards peace and harmony with nature, are the key similarities [12]. One of the underlying beliefs of ecopsychology is that our present problems are the result of the Western paradigm where human beings believe they are the dominant life form. This relates in part to how the treatment of women arose over time discussed in the previous section $[4,5,12]$. The derivation of the belief structure stemmed from human attempts to dominate and control nature. This perspective, also similar to the discussion of women in the previous section, has been linked to a community viewpoint where individuals or communities who seem to be nearer to nature, such as indigenous communities, women, some minorities and working classes are also simultaneously oppressed [5].

Ecopsychology can also be viewed in the internal world where instinct and intuition, aspects of human culture often linked with feminine qualities and nature, are typically devalued or suppressed [6]. Authors have also linked ecopsychology through how corporations are run, how political policies are constructed, and how some people live in harmony with nature. Corporations and politics appear to have a fear of nature or treat nature in general as if it were something for human beings to use as they wish rather than something that should be treated fairly and equitably [6]. Merchant [13] indicated how complex the assessment of the theory of ecopsychology can be since there is a dynamic nature to the shifting patterns of existence between and among humans and nature throughout both time and across cultures.

The link between human existence and the existence of nature is also viewed through the ecopsychological perspective with respect to the relative longevity of the perceivers [6]. For example, humans may have developed a confrontational and domineering attitude towards nature as a result of the relatively short timeline of human existence with respect to geological timeframes. Other species, millions of them, have lived in complete harmony with nature since the first organisms developed from amino acids billions of years ago. Human beings are the first species to attempt to dominate nature and rise above it, both literally and figuratively [14]. The industrial revolution provided a period of time where human beings went from living in relative harmony with nature, for example living in a sustainable manner with their surroundings, to viewing natural resources as a means to an end through technological advancement. The transition between the steam engine, which ran on vaporized heated water, to the coal fired engine, marked the first significant demarcation in how humans went from viewing nature as an equal to viewing nature as something to be used to an end [14].

So while human society in general has tended in most part to view females as subordinate or below males, the same has not been true throughout history for nature. Instead, it is only in the past few centuries that human beings have viewed themselves as rising above nature and it's during this time that the linkage between the oppression of females and the oppression of nature has been viewed in the same light [6].

\section{Ecopsychology and Feminism: Ecofeminism}

Authors since the 1980s have linked the concepts of ecopsychology and feminism to create a new construct of ecofeminism. There has been a bifurcation across gender lines that was drawn and through this lens; it was perceived that there was a parallel split between nature and humanity and between women and men. In addition to the core concepts of how nature is often treated in a similar oppressive fashion, there are cultural viewpoints that indicate that nature itself is a female concept [5].

Socialists and Marxists are also famous for sharing some key concepts with ecofeminism in that Marxists adopted a more equitable 
perspective of nature. They saw nature moving from a resource that drove production to a means through which society could become self-sustaining. Nature would not be valued through its usefulness but instead through how humans and nature could live in a mutually beneficial fashion. The present actions of developed society do not align with this more equitable viewpoint [9]. Instead, what has been witnessed over the past few centuries is an alignment of how maledominated society treated nature and how male-dominated society treated women.

While we live from nature, we have evolved into a species that is near the brink of starting its own downfall through the way in which it relates to nature [9]. This manner of conquering nature is also seen in how many societies treat women. While the trajectory of these two constructs, those of dominating nature and dominating women, are divergent, the end result of the ecopsychological perspective remains valid. Women have gained more rights, more equality, and are treated less like a subordinated gender. On the other hand, some facets of society are adopting a vegan lifestyle, a communal lifestyle, and a lifestyle that is aligned with a non-resource depleting fashion of existing with nature. These facets of society, however, are in the very small minority [11]. As a result, the predominate viewpoints and the predominate factors that drive cultural advancement are those that still see nature as something to use for humans' benefits. Human beings have treated nature as an enemy and the way in which we live is such that our profit-driven culture (capitalism is the most predominate social order currently) has created side effects that harm nature. These include racism, poverty, globalization, imperialism, and community destruction. All of these factors can lead to an increasing degree of harm that comes to nature [11]. Recently is the first time that there is some degree of consciousness regarding the depth of the crisis and the kind of transformation which will have to occur to ensure the survival of human beings.

While the human race's survival is different than the overall treatment of women, there are similarities that are important to note and that are important to construct an analysis of how male-dominated society relates to both women and nature. First, ecofeminism indicates that there exists a difference between nature and humanity, which in turn reflects the differences between females and males [3]. This differentiation is supported by a power hierarchy that is dualistic in nature and which provides an overview of "interwoven oppression". This worldview includes the perspective in which humans are inherently superior to nature in the same sense that men are biologically superior to women.

According to this perspective, hierarchical rankings that are based on a concept of inherent superiority are inseparable [3]. The fact that there is a perceived value based hierarchy of existence and that this hierarchy presupposes an oppressive ranking structure is a view whose assumptions are so widely accepted by modern culture that it is not generally questioned much less thought of as a powerful sociopolitical ideology [6].

The second significant theme that derives from ecofeminism is the conviction that the relationship between humans and nature and various factors of social domination are feminist concerns [6]. For ecofeminists, the present power structures that exist are all in need of an overhaul and are all in need of logical critiquing. This assessment would be the first stage in developing a new face of the natural and human interrelationship. These critiques are seen as important for change to occur since both nature's destruction and female oppression and violence step from the powerlessness that the present power structures perpetuate [7]. As a result, there is no ethic that involves anything other than a new relationship between nature and man. Any ecological ethic must always take into account the structures of social domination and exploitation that mediate domination of nature and prevent concern for the welfare of the whole community in favor of the immediate advantage of the dominant class, race, and sex [7].

The movement of ecofeminism provides the justification for the relinquishment of power by male-dominated society as it attempts to develop grassroots political action that has the potential to alter the way both women and nature are treated. The purpose of the movement is not violent though and no violence should be used in the overhaul of society's morals and ethics [9]. Instead, the non-violent power transformation should be viewed as a means of replacing the current male-dominated and self-defeating humanistic approach to nature with one that provides an improved and more equal relationship between the sexes and between human beings and nature.

The third theme that has emerged in the ecofeminist philosophy is that of interconnectedness between societal actors. Interconnectedness for ecofeminists is a perspective in which matter, reality, and energy are part of a larger whole. All things are connected in complex webs of communal networks [9]. This whole is not an abstract mentalism but has infinitely complicated characteristics somewhat analogous to the way communities of manage individual and collectivist realities.

Writers of ecofeminist philosophy have purported the concept that human beings have lost their ability to be one with nature or live in harmony with nature through a decrease in awareness that was initiated and perpetuated by modern economies, institutions, and education. Kheel [5] also compared the fragmented modern psyche with a frontal lobotomy, which reduces a person's fundamental cognitive and sentient powers by significant degrees. This deficiency began with the introduction of positivist scientific strategies and is sustained through all other educational and economic processes based on positivist premises [5]. The educational system, as a result, reduces the ability to think independently and without the scientific rigor that is sustained and perceived to be needed for the inventions that society so highly values. Griffin [8] also suggested that the modern civilization is mostly divided rather than connected and the educational system played a major role in that development over the past century. The scientific method of thinking taught in schools, while it does not directly relate to feminism, can be seen as a link between man's destruction of nature and the underlying constructs that permit such an occurrence.

Ecofeminists also understand human beings as not being separate from or above nature. Humans are part and parcel of nature rather than separate from or above it [8]. When people separate themselves from nature, there is a lack of consciousness that can develop with respect to not being fully aware of how individual actions relate to each other in a meaningful fashion. In addition, the link between how male-dominated society treats nature and women has been likened to how human beings have become less concerned with their souls [8]. This is not to say the religious structure of a soul is important, but instead that the concept of something greater than human beings exists and should be nurtured. The sense of nurturing a soul is something that can help reduce the factors that lead to both oppression of nature and oppression of women. In short, Griffin [8] viewed caring as a key factor in how to develop a more fundamentally sound and sustainable relationship between maledominated society and nature and male-dominated society and women.

Several important premises may be distilled from ecofeminist philosophy. One, by defining nature as other and essentially hostile, or by hierarchically relegating it to a position of lower rank, humanity simultaneously defines itself in a way that severely constricts its ability 
to create individual and collective meaning. The reality is that there is no value-based hierarchal ordering of nature and no natural antagonism and separation between humans and nature. Nature is one with and beneficial for humanity [5]. A second premise derived from ecofeminism is that in large measure social, political, economic and environmental issues are interrelated and fundamentally associated with humanity's philosophical understanding of its relationship with nature and the practices that stem from it. By constructing an integrated language of person and nature, one that fully incorporates the powerful image of interconnectedness, social work enhances its ability to understand and thus act upon a broader range of human issues [8]. Adopting an alternative metaphor of human and nature's relationship, for example that of a nurturing mother who kindly provides for the needs of her children, suggests something uniquely different and transformative in the way humans sense their place with the larger natural environment and their place in the community of being. It dramatically reconstructs a capricious and dangerous nature into a nature that provides life-giving and life-sustaining nourishment [8].

\section{Discussion}

While women have gained significant traction over the past century including suffrage, workplace equality in terms of treatment, and freedom from some stereotypes, the reduction in degree and frequency of oppression and violence has not removed it from the specter of human existence. The male-dominated society remains a means of controlling, to at least some degree, the female role in society. Similarly, the male-dominated society views nature as a means to an end, or at the very least as an unequal factor necessary for existence. Formerly, in hunter and gatherer societies, while women were marginalized and nature was not, there was no source of ecofeminism; however, as society shifted as a result of the industrial revolution, and as natural resources become something necessary for the advancement of human society, the domination of nature by male-dominated society become just as noticeable as the male domination of women has been over thousands of years. The ecopsychological perspective provides an important viewpoint through which it is possible to see how society treats, interacts, and dominates nature in a similar fashion through which women have been oppressed and mistreated for long periods of time. The way this can be improved is to become a more caring society.

\section{Conclusion}

The previous discussions provided an introduction to ecopsychology, oppression and violence against women, and the combination of ecopsychology and feminism to create ecofeminism. The purpose of this paper was to examine the link in the literature between oppression and violence against women and society's behavior towards nature. Male-dominated society was presented as a form of society that evolved over time. Initially, while the origins remain in a state of discussion, hunter and gatherer societies found that men and women had different roles. Women's roles relegated them to areas and activities that led to minimal interaction with our societies or cultures. Men's roles put them front and center in an aggressive hunter construct that led to the development of power and accumulation of wealth. From this vantage point, male-dominated society has remained unchanged over thousands of years in terms of viewing women's roles in society as unequal to those of men [15-20].

\section{References}

1. d'Eaubonne F (1994) A time for ecofeminism. In: Merchant C (ed.), Key concepts in critical theory: Ecology. Humanities Press, Atlantic Highlands, NJ. pp: 174-197.

2. Cheney J (1987) Eco-feminism and deep ecology. Environ Ethics 9: 115-145.

3. Biehl J (1988) What is social ecofeminism? Green Perspectives 11: 3

4. Berman T (1994) The rape of mother nature: Women in the language of environmental discourse. Trumpeter 11: 173-178.

5. Kheel M (1991) Ecofeminism and deep ecology: Reflections on identity and difference. Trumpeter: Journal of Echospy 8: 62-72.

6. Mathews F (1994) Relating to nature: Deep ecology or ecofeminism? Trumpeter 11: 159-166.

7. Warren K (1990) The power and promise of ecological feminism. Environ Ethics 12: $125-146$

8. Griffin S (1990) Curves along the road. In: Diamond I, Orenstein G (eds.) Reweaving the world: The emergence of ecofeminism. Sierra Club Books, San Francisco. pp: 87-99.

9. Salleh A (1992) The ecofeminism/deep ecology debate: A reply to patriarchal reason. Environ Ethics 14: 195-216.

10. Lerner G (2005) The majority finds its past: Placing women in history. University of North Carolina Press, Charlotte, North Carolina.

11. Anthony C (1995) Ecopsychology and deconstruction of wholeness. In: Roszak T, Gomes M, Kanner A (eds.), Ecopsychology: Restoring the earth healing the mind. Sierra Club Books, San Francisco. pp: 263-278.

12. Besthorn FH (2001) Transpersonal psychology and deep ecological philosophy: Exploring linkages and applications for social work. Social Thought: Journal of Religion in the Social Services 20: 23-44.

13. Merchant C (1994) Key concepts in critical theory: Ecology. Humanities Press, Atlantic Highlands, NJ.

14. Queralt M (1996) The social environment and human behavior: A diversity perspective. Allyn and Bacon, Boston.

15. Capra $F$ (1996) The web of life: A new scientific understanding of living systems Anchor Books, New York.

16. Christ C (1990) Rethinking theology and nature. In: Diamond I, Orenstein G (eds.), Reweaving the world: The emergence of ecofeminism. Sierra Club Books, San Francisco. pp: 58-69.

17. Fox W (1989) The deep ecology-ecofeminism debate and its parallels. Environ Ethics 11: 5-25.

18. Fox W (1995) Toward a transpersonal ecology: Developing new foundations for environmentalism. State University of New York Press, New York.

19. Skolimowski H (1990) For the record: On the origin of ecophilosophy Trumpeter: Journal of Ecosophy 7: 44-48.

20. Zastrow C, Kirst-Ashman KK (1997) Understanding human behavior and the social environment. Nelson-Hall, Chicago. 